\title{
PHYSICAL EXERCISES FOR PRE-SCHOOL CHILDREN WITH HOMEWORK AND PARENTS MOBILIZATION AROUND THESE TASKS
}

\author{
KRZYSZTOF PIECH ${ }^{1}$, KAROLINA NOWAK ${ }^{1}$, ZINA BIRONTIENE ${ }^{2}$, INTA BULA-BITENIECE ${ }^{3}$ \\ ${ }^{1}$ The Josef Pilsudski University of Physical Education in Warsaw, \\ Faculty of Physical Education and Sport in Biała Podlaska, Department of Tourism, \\ ${ }^{2}$ Klaipeda University, Chair of Physical Education \\ ${ }^{3}$ Latvian Academy of Sport Education in Riga, Chair of Theory
}

\author{
Mailing address: Krzysztof Piech, Faculty of Physical Education and Sport, Department of Recreation, \\ 2 Akademicka Street, 21-500 Biała Podlaska, \\ tel.: +48 83 3428758, fax: +48 83 3428800, e-mail: krzysztofpiech@wp.pl
}

\begin{abstract}
Introduction. Results presented in this article are part of an international project called Project of physical activity stimulation in a family (PPASF) held jointly with the Klaipeda University and LASE in Riga. We decided to check whether participation of children in preschool age in active classes in nursery school may be an impetus to change behavior in terms of physical activity of a family. For this purpose, a model was developed that included physical activity program conducted in the nursery school, with homework for the children to do together with their parents at home. The aim of the study was to examine the extent to which a child can persuade the parents to a common physical activity and whether sport and recreation for children with homework are a successful proposal to increase motor activity of the family. Material and methods. A diagnostic survey method was applied in the research, using a questionnaire technique. The survey questionnaire covered 38 families including 30 mothers and 8 fathers. Results and conclusions. Research has shown that children can become facilitators of physical activity in the family. The proposed model classes for children proved to be an accurate proposal, which is worth to implement the practice of teaching.
\end{abstract}

Key words: family, child, physical activity

\section{Introduction}

In the past, physical activity conditioned survival of the individual. To function in the harsh world, humans had to run, track down prey. Along with civilization development, the man noticed that physical forces can be replaced by the mental capacity and began to limit physical activity. The progress in medicine and technology has increased the length of life of the people, but to a large extent increased the cost, which is often a very large financial burden on the budgets of individual countries. Many diseases of civilization absorb considerable resources because they force people, often at a young age, to take medication and cause their absence from work. Therefore people are looking for ways to change this state of affairs. Numerous scientific evidence about the importance of physical activity for human health encourage search for solutions in the field of physical culture. In this article, we wanted to draw attention to the importance of the family in promoting of healthy, active lifestyle. Family, as considered by many authors, is the primary education environment for recreation. Previous studies on physical activity in the family showed this issue from the point of view of parents' influence on children. The more active parents the more active children. Many authors undertook studies in this area [1, 2, 3, 4, 5, 6, 7].

Aspect of the impact of physical activity of parents on the activity of children is dominant in current research in this field. Occasionally topics are taken up that look at this phenomenon from the point of view of small child, i.e. how a child can persuade a parent to physical activity.

This topic has been taken in these studies .

\section{Material and methods}

We decided to check whether participation of preschool children in activity classes in the nursery school may constitute an impetus to change family behaviour in terms of physical activity. For this purpose, a model was developed that covered physical activity program conducted in nursery school with homework to do by children together with their parents at home. The aim of the study was to examine the extent to which a child can persuade the parents to a common physical activity and whether sport and recreation for children with homework are a successful proposal to increase motor activity of the family.

Research questions which were raised for that purpose include the following:

1. What are the most common forms of physical activity undertaken by parents together with their children?

2. How often physical activity is undertaken in the studied families?

3. Do the proposed sport and recreation for children cause change of behaviour of family physical activity?

4. Do children inform their parents what activities they attended while in the nursery school?

5. Do parents do the homework together with their children?

6. Does the joint undertaking physical activity of the child and parents encourage purchase of a new leisure and sporting equipment?

The research was a part of an international project called Project of physical activity stimulation in a family (PPASF) held jointly with the Klaipedda University and LASE in Riga [8]. Research is a continuation of research conducted in 2000-2009 
under the theme "child - the animator of physical activity in the family" $[9,10]$. In the period between October 2011 and January 2012 there were physical activities of recreational and sports nature conducted for children from The Julian Tuwim Local Government Nursery School No. 15 in Biała Podlaska. Regularly once a week, on Friday, classes were conducted in 4 groups of about ten children. Classes lasted 30 minutes. The classes covered girls and boys from groups of five and six year old children. There was a total of 38 children. Physical activities carried out in the nursery school had its continuation in the form of frequent homework to do at home by the children and their parents. After each session, the person conducting the classes asked the children to convey information about the homework to their parents. For this purpose, a special proprietary model of physical activity for children with homework of variable themes was developed. The child acted both as a participant and intermediary in the transmission and encouraging the implementation of joint exercises. Homework included games, fun and exercise of differing themes, relevant to the prevailing season. In the study the diagnostic survey method was applied using a technique of questionnaire for parents. Questionnaires were anonymous, contained open and closed questions giving respondents the opportunity to express themselves freely; they have been filled by one of the parents. Noting that data collected exclusively from the questionnaire will not show all the relevant details of the problem undertaken, in order to increase reliability and to obtain the necessary information, further research was applied, using other techniques such as the analysis of children's drawings.

The survey questionnaire surveys have covered by 38 families including 30 mothers and 8 fathers. Respondents returned all the questionnaires. $17.1 \%$ of the respondents had vocational secondary and secondary schools education. The smallest group is those with primary education (7.9\%). Undertaking physical activity can take many forms. One of them may be a way how a child is delivered to the nursery school. According to the declarations of the respondents, more than half of the children are being transported to the nursery school by car (52.6\%). In 13 families the custodians decided on bringing the child by foot (34.2\%). Respondents frequently pointed to buses as "other" ways of delivering the child to the nursery school. One of the subjects used bicycle for this purpose.

\section{Results}

\section{Leisure activities of the surveyed families}

The study shows that nearly one third of all parents undertake physical activity rarely $(27.8 \%)$, and two times a week $(26.4 \%)$, of which more often in both cases are mothers than fathers. Daily physical activity is undertaken by only one fifth of all parents $(22.2 \%)$ at the same time it was noted that more often these are the fathers (26.3\%) than mothers $(15.8 \%)$ (Fig. 1).

The amount of space available for the fun and exercise at home is an important component of physical activity of family members. According to 34 respondents (89\%), the amount of space to take up physical activity and have fun with the child in their home is sufficient. Only four persons have indicated that they do not have sufficient facilities to have fun with their child.

The surveyed parents rated the level of physical activity of their child as high. According to more than half of parents (57.9\%), their child is physically active. One of the parents rated the child as "very physically inactive". Please note that these are declarative data of the parents and may not reflect the actual real physical activity level of the children (Fig. 2).

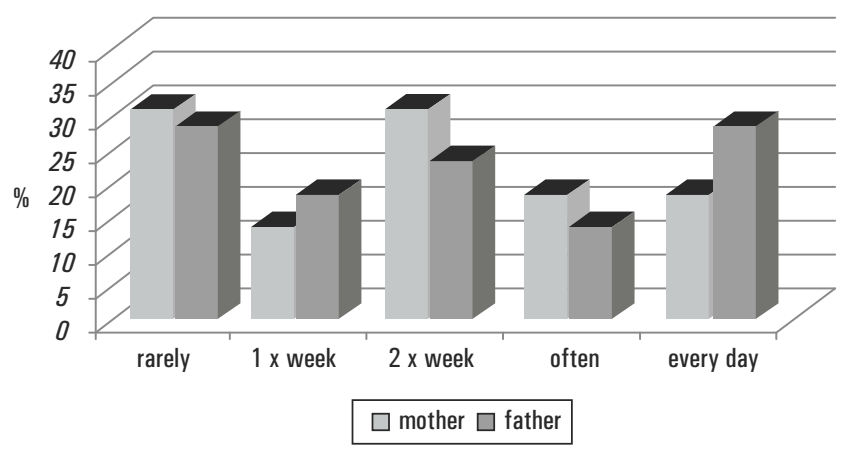

Figure 1. The frequency of parents undertaking physical activity $(\%$ for $n=38)$
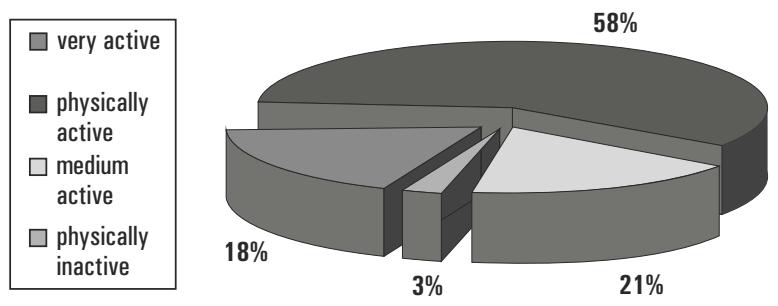

Figure 2. The level of physical activity of the child, in the opinion of parents ( $\%$ for $n=38$ )

In further analysis of the responses one could expect that a child can be a good inspiration for physical activity of the parents. According to the 29 parents, their child often asks for a joint fun (76.3\%). Only four children never made such attempt (Fig. 3). This demonstrates the need for physical activity exhibited by the children and the desire to have fun with a parent.

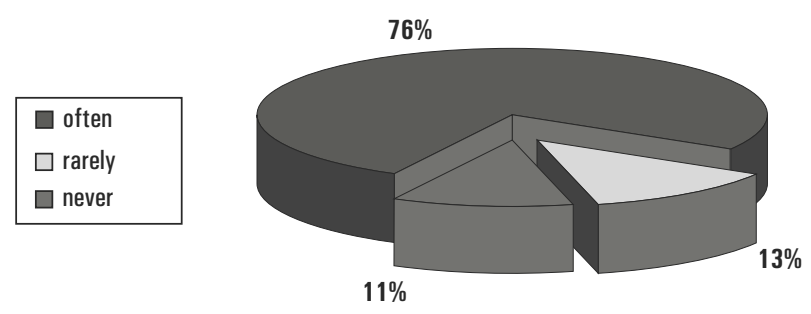

Figure 3. Does the child ask for common play ( $\%$ for $n=38$ )

Research has shown that parents spend very little time on common physical activities with the child. Only a quarter of parents play with their child every day $(10.5 \%)$ or at least $3-4$ times a week (10.5\%) (Fig. 4). In addition, the key was to obtain the information who is playing with a child most often. It was found that people most often playing with their children are the mothers (55.3\%), subsequently other persons $(23.7 \%)$ indicated by the respondents: grandmothers, grandfathers, and siblings. The share of father in common fun was limited.

Another issue of interest to us is the kinds of activities undertaken by the children (Tab. 1). Most of them often and very often run, play with elements of running, jumping, playing with a ball, practice balance, and ride a bike. During the winter season children play in the snow, use sleds and ice skates. A positive development is the fact that children tend not to spend a lot of time playing on the computer. It is speculated that it may result from the rules of the computer use set up by parents, and not only from the voluntary will of the child. 


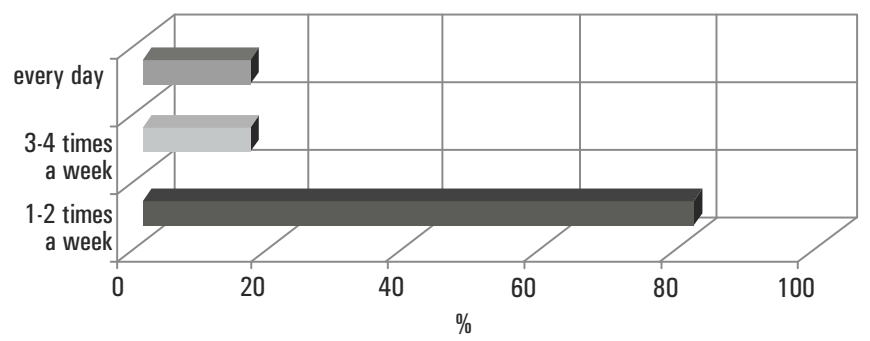

Figure 4. The frequency of playing with the child ( $\%$ for $n=38$ )

Table 1. Forms of child's activity in the last month

\begin{tabular}{|l|c|c|c|c|c|}
\hline \multicolumn{1}{|c|}{ Activity } & Never & $\begin{array}{c}\text { Very } \\
\text { rarely }\end{array}$ & Rarely & Often & $\begin{array}{c}\text { Very } \\
\text { often }\end{array}$ \\
\hline Run, plays with elements of running & 0 & 0 & 4 & 28 & 6 \\
\hline Crawling, jumping & 0 & 4 & 10 & 16 & 8 \\
\hline Computer fun & 4 & 12 & 14 & 6 & 2 \\
\hline Ball games & 0 & 4 & 12 & 18 & 4 \\
\hline Balance exercises & 0 & 10 & 16 & 12 & 0 \\
\hline Roller-skating, bicycling & 6 & 16 & 6 & 8 & 2 \\
\hline Ice-skating, sled riding & 4 & 4 & 10 & 20 & 0 \\
\hline Games on the snow & 2 & 4 & 6 & 20 & 6 \\
\hline
\end{tabular}

The results indicate that the majority of children involved in the study participate in more physical activities (63.2\%) organized by other institutions. These are the most commonly classes of corrective gymnastics, sports gymnastics, dancing, eurhythmics, and swimming. This shows that parents transfer the obligation of the common physical activity with children to various institutions.

Sports and recreation activities for children with homework as a form of promotion of physical activity in family

In examining the impact of participation in sports and homework on increase of physical activity of the whole family we had to assess whether parents previously undertook physical activities with the child. The analysis of the data shows that as many as $60 \%$ of parents did not undertake this kind of activity with the child (Fig. 5).

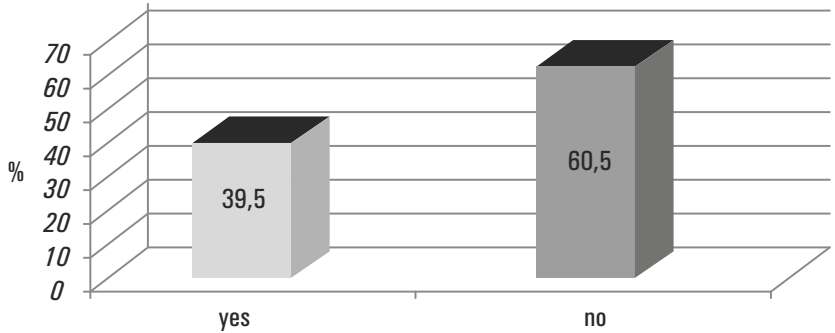

Figure 5. Were the parents involved in some sort of physical activity with the child before adoption of physical activity for children with homework?

Ready sets of exercises and activities that the children received to do with their parents were to inspire and encourage to take steps aimed at increase of physical activity of the family. It is important whether the children informed their parents about the selected homework and talked about their activities after returning home (Fig. 6).

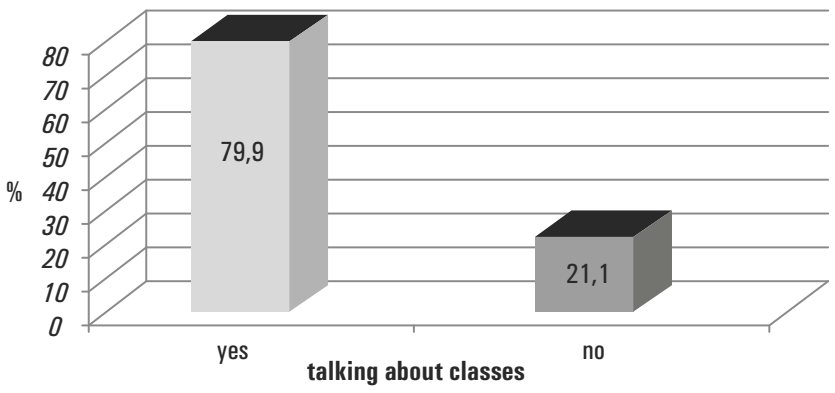

Figure 6. Talking about classes and homework after returning home (\% for $\mathrm{n}=38$ )

Not all children addressed the topic of sports and recreational activities in the nursery school and homework. An important element in the whole research process was the fact whether the parents after receiving information from a child did the homework together (Fig. 7). Unfortunately, many of them (31.6\%) did not take such action.



Figure 7. Implementation of the homework ( $\%$ for $n=38$ )

At the same time we asked what was the reason for not implementing of these tasks (Fig. 8). Of the 12 persons who did not declare "doing" the homework, more than half said that they did not have time $(66.7 \%)$, the rest were not willing $(25 \%)$ or simply forgot (8.3\%).

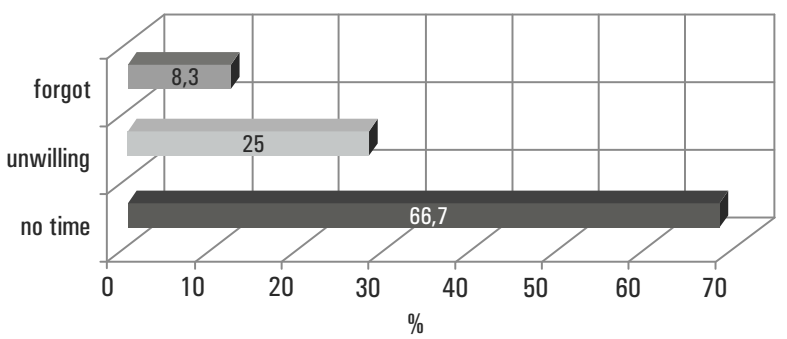

Figure 8. Reasons for not doing the homework ( $\%$ for $n=12$ )

As follows from the analysis of data from persons who did homework, the largest share in homework had the mothers (30.8\%) (Fig. 9). Comforting is the fact that other family members such as grandparents also enjoyed joint exercises. Also, the whole family involvement in a common physical activity is high (23.1\%).

It was also important how often the parents are involved in the implementation of homework after classes (Fig. 10). Most of the subjects performed tasks 1-3 times a week (76.9\%). 


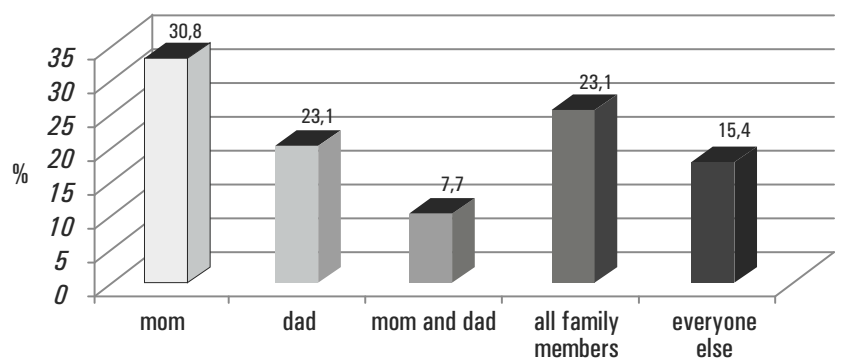

Figure 9. Family members who did the homework ( $\%$ for $n=26$ )

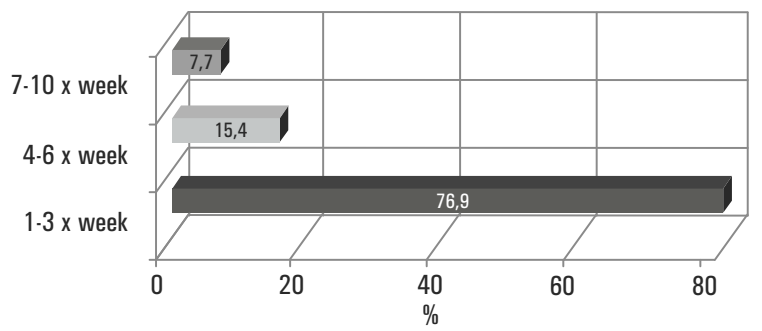

Figure 10. The frequency of doing homework ( $\%$ for $n=26$ )

For all parents engaging in homework (68.4\%) shared fun with a child was a source of additional experiences and sensations. As they admit, they could get to know their child better, become aware the yet undiscovered possibilities of the child, realize that the child will be healthy and athletic, and the time spent together is a great value and strengthens family ties. According to $52.6 \%$ of respondents, participation in this program contributed to the increase in physical activity of the family, $36.8 \%$ said that their activity has increased on the Saturdays and Sundays, while $15.8 \%$ of respondents think physical activity has increased every day (Fig. 11).

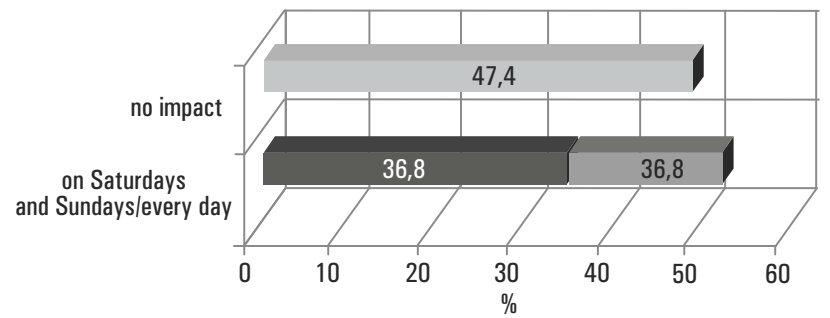

Figure 11. The impact of participation in the program on the increase of physical activity of the whole family ( $\%$ for $n=38$ )

Less than $16 \%$ of respondents admitted that activities had impact on the purchase of new sports equipment. According to the others, purchase of equipment was not needed or they did not feel such a need (Fig. 12). This is probably due to the fact that homework aimed at the use of everyday objects. The idea was not to expose the family covered by the study to costs, and at the same time stimulate the imagination and creativity of family members.

In addition, before and after the sports and recreational activities the children were asked to submit a drawing of leisure time spent at home. Theme of the work was: "My leisure time after returning home from nursery school". According to psychologists, a drawing made by a child is not just a set of symbols but encrypted code of emotional and developmental status of the child. Here is an example of one of the drawings in which the child does not take parents into account. This may prove that after returning home the child usually plays alone. The drawing made after completion of the course brings about the conclusion that the child spends more time playing together with a parent. The central position of the main elements confirms sense of security, and presenting the guardian next to the child is a sign of family ties. The situation on the drawing shows a common play at home while doing homework.

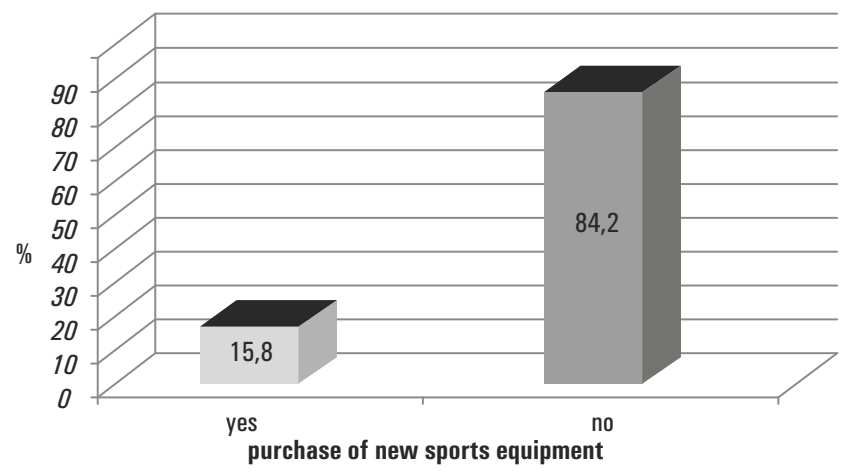

Figure 12. Participation in the program and the purchase of sports equipment ( $\%$ for $\mathrm{n}=38$ )

\section{Summing up and conclusions}

Studies of physical activity in family usually concern the impact of the activity of parents on their children's physical activity. It is emphasized that the more active parents are, the greater opportunity to pursue a similar style of life by children in the future [11]. Physically active parents are a good role model for their children [12, 13]. According to Hurlock, a child will never get rid of the basic pattern adopts in the family, although it may be subject to modifications and variations [14]. Hence the recreational function of the family is becoming increasingly important. Another problem that occurs much less frequently in studies of physical activity is the issue of children's activity influence on the activity of their parents. Research carried out by a few authors confirms that the child may be an animator of family physical activity [8, 9, 10, 15, 16]. Respondent parents both in Latvia and Lithuania indicate a lack of time as the main reason for the lack of physical activity with the child. Parents also confessed to laziness. Both our study and Birontiene [8, 17] established that children talk about the homework and encourage parents to effectively carry out the tasks. Adults indicated $(52.6 \%)$ that the common physical activities caused a positive change in the behaviour of the family. Prior to the program, only $39.5 \%$ of the respondents declared that they shared physical activity with the child. This number has increased after our classes. Research shows that 15\% of parents purchased sports equipment after participation in the program. In previous studies on participation of parents and children in sports and recreational events we obtained index above 56\% [9]. Therefore, it can be argued that the physical activity program for children with homework is a good way of promoting physical activity among families. These types of programs can contribute to the development of a model of physical activity of parents with young children $[18,19,20]$.

The studies lead to the following conclusions:

1. Children can be facilitators of family physical activity, as they convey information on the activities taking place in the nursery school and effectively encourage the implementation of homework.

2. Common exercise and homework is a source of positive sensations and experiences in families, and is an important process in preparing children to participate in physical culture. Organizations dealing with the organization of leisure time should use this educational process.

3. Parents undertaking a common physical activity with 
a child noticed a huge role and need of child's physical activity. It seems reasonable to incorporate a wider variety of programs that promote family physical activity in preschool age. One should educate the parents and caregivers in the field of physical activity of the whole family during various meetings and conferences organized in nursery schools and schools, showing not only the health aspects of physical activity but also the integration-emotional benefits for the family.

4. The proposed model of classes for children proved to be an accurate offer, which is worth using in education.

5. Further research should be focused towards the search for new models of physical activity in the family. One should also pay more attention to cooperation between the physical culture of preschool education environment and the parents.

\section{Literature}

1. Dempsey J.M., Kimiecik J.C., Horn T.S. (1993). Parental influence on children's moderate to vigorous physical activity participation: An expectancy-value approach. Pediatric Exercise Science 5, 151-167.

2. Brustad R.J. (1993). Who will go out and play? Parental and psychological influence on children's attraction to physical activity. Pediatric Exercise Science 5, 210-223.

3. Bois J., Sarrazin P. (2006). Les chiens font-il des chats? Une revue de literature sur le role de parents dans la socialization de leur enfants pour le sport. Science et Motricite 57, 10-54. [in French]

4. Bula-Biteniece I. (2011). Holistic approach in family sport in pre-school education. Doctoral thesis, Latvian Academy of Sport Education, Riga.

5. Wolańska T., Marczewska H. (1988). Family as the environment of educating for physical education. In T. Wolańska (Ed.), Education for physical recreation (pp. 28-86). Warszawa: AWF Warszawa. [in Polish]

6. Alderman B.L., Benham-Deal T.B., Jenkins J.M. (2010). Change in parental influence on children's physical activity over time. Journal of Physical Activity and Health 7, 60-67.

7. Moore L.L., Lombardi D.A., White M.J., Campbell J.L., Oliveria S.A., Ellison R.C. (1991). Influence of parents physical activity levels on activity levels of young children. The Journal of Pediatrics 118(2), 215-219.

8. Birontiené Z. (2012). A child as a physical activity stimulator in a family. Sporto Mokslas 2(68), 38-45.

9. Piech K., Baraniecka D. (2011). The child as family animator of physical activity. LASE Journal of Sport Science 1(2), 2533.

10. Piech K. (2012). Olympics games for preschool children with educational workshops for preschool teachers, parents and children. Issue 3. Warszawa: Klub Fair Play PKOL. [in Polish]

11. Drabik J. (1995). Physical activity of children, adolescents and adults. Gdańsk: AWF Gdańsk. [in Polish]

12. Iannotti R., Sallis J.F., Chen R., Broyles S.L., Elder J.P., Nader P.R. (2005). Prospective analyses of relationships between mothers' and children's physical activity. Journal of Physical Activity and Health 2, 1-34.

13. Sigmund E., Turonova K., Sigmundova D., Pridalova M. (2008). The effect of parents' physical activity and inactivity on their children physical activity and sitting. Acta Universitatis Palackianae Olomucensis. Gymnica 38(4), 17-23.

14. Hurlock E.B. (1960). Child development. Warszawa: PWN. [in Polish]

15. Bula-Biteniece I., Grants J., Jansone R. (2010). Habits of physical activities in families (empirical investigation). Sporto Mokslas 3(61), 13-18.
16. Staniszewski T. (2007). Assumptions and the actual functions of the school in preparing children in early school age to physical recreation in a family. Warszawa: AWF Warszawa. [in Polish]

17. Birontienè Z. (2012). Stimulation of physical activity in families with preschool children and opportunities of Olympic education in preschool institutions. Sporto Mokslas 4(70), 14-21.

18. Starosta W. (1991). Model of comprehensive motor education of a Polish child in family. Warszawa: International Association of Sport Kinetics.

19. Berdychowa J. (1972). Mom, dad, exercise with me. Warszawa: SiT. [in Polish]

20. Siwiński W. (2000). Outline of pedagogy of physical culture. Poznań: AWF Poznań. [in Polish]

Submitted: June 21, 2013

Accepted: August 30, 2013 